\title{
Micropunched microholes potential for bioapplications
}

\begin{abstract}
Microholes punched by tungsten carbide + cobalt micropunch $(150 \mu \mathrm{m}$ in diameter) in various processing periods were studied. The relationship between the morphology of microholes and the punching numbers with titanium as substrate had been investigated by confocal laser, scanning electron microscopy (SEM), energy dispersive X-ray analysis (EDX), optical surface profiler (OSP), etc. Results show that in the initial micropunch processing, some debris obviously distribute on both sides of the punched microhole because of the un-stabilization of the size of the micropunch, especially for the front side. Consequently, the formed microholes cannot have the high quality. While the micropunch is in the quasi-stable period, owing to the effective jointcontribution of WC and Co distributed in the micropunch, the profile and the size of the punched microholes are distinctly better than that of the initial period along with a little wear loss of the micropunches. However, with the increment of the punching number further (e.g.>1525), the quality of punched microholes decreases remarkably with the micropunching failure. At the same time, due to the vanishment of the favorable joint-contribution of $\mathrm{WC}$ and $\mathrm{Co}$, WCs, the dominantly relied factor in the sever period, are easily peeled off because of the serious loss of Co. More interestingly, the punched microhole in the quasi-stable period can be used directly without any post treatments which is the potential for bioapplications.
\end{abstract}

Keywords: microhole, micropunch, profile, diameter, wear, bioapplication
Volume 2 Issue 3 - 2018

Kelvii Wei GUO

Department of Mechanical and Biomedical Engineering, City University of Hong Kong, China

\begin{abstract}
Correspondence: Kelvii Wei GUO, Department of Mechanical and Biomedical Engineering, City University of Hong Kong, 83 Tat Chee Avenue, Kowloon Tong, Kowloon, Hong Kong, China, Email kelviiguo@yahoo.com
\end{abstract}

Received: June 22, 2018 | Published: June 28, 2018
Abbreviations: OSP, optical surface profiler; SEM, scanning electron microscopy; EDX, energy dispersive X-ray analysis

\section{Introduction}

Advances in tele-communication, transportation and medical fields lead to challenges in micro fabrication, miniaturization and multi-functional technologies in manufacturing. Feature sizes are in the range of a few microns up to hundreds of microns. ${ }^{1-4}$ Ability to fabricate micro holes in large quantities has potential applications in medical implants, diagnostic and remediation devices, micro-scale batteries and fuel cells, fluidic microchemical reactors requiring micro-scale pumps, valves and mixing devices, micro-fluidic systems, cooling holes in jet turbine blades, fiber optics, micronozzles for higher energy efficiency and less pollutant emissions to the environment, ${ }^{5-7}$ micro-molds and deep X-ray lithography masks, optical lenses, and micro components in daily life products such as compact disc players, air bags and inkjet printers. Currently, with the ever increasing demand for smaller, higher-quality and lower-priced products from almost all fields of industry, household equipment and entertainment electronics, the development of manufacturing methods which are tailor-made for the micro systems technique with higher precision, lower cost, larger quantities, more eco-friendly to environment are extremely urgent. Investigators have looked for various methods for the manufacturing of miniature parts. ${ }^{8,9}$

The trend for micromanufacturing is more focused on miniaturizing or down-scaling both conventional and non-conventional methods to produce microproducts. Manufacturing processes can be categorized according to the type of energy used in the process itself, such as mechanical, chemical, electrochemical, electrical and laser processes. The working principles behind each process include consideration of mechanical forces, thermal effects, ablation, dissolution, solidification, recomposition, polymerisation/lamination, and sintering. According to the way in which components/products are to be made, general manufacturing processes can also be classified into subtractive, additive, forming, joining and hybrid processes. The classification is equally applicable to micromanufacturing. For subtractive processes, there are micromechanical cutting (milling, turning, grinding, polishing, etc.), micro EDM, micro ECM, laser beam machining, electron beam machining and photo-chemical-machining; For additive processes, the relevant techniques are surface coating (CVD, PVD), direct writing (inkjet, laser-guided), microcasting, microinjection moulding, sintering, photo-electron-forming, chemical deposition, polymer deposition and stereolithography; For deforming processes, there are micro forming (stamping, extrusion, forging, bending, deep drawing, incremental forming, superplastic forming, hydro-forming, punching), hot embossing, and micro/nano-imprinting; For joining processes, the related techniques are micro-mechanical-assembly, resistance, laser, vacuum soldering, bonding/welding, and gluing; For hybrid processes, there are micro-laser-ECM, LIGA and LIGA combined with laser machining, micro-EDM and laser assembly, shape deposition and laser machining, laser assisted micro forming, micro assembly injection moulding, combined micromachining and casting. ${ }^{10-17}$

Punching is the process of forcing a punch through the material and into a die to create a hole in the work piece, and the most popular method for fabricating holes for mass production. It is often an economic way of creating shaped holes in mass production. It also offers some attractive characteristics that are superior to those of other processes, for example, machining and chemical etching, considering such features as high production-rates, better material integrity, less waste, lower manufacturing costs, etc. Therefore, micropunching is a 
better option for the mass-manufacture of microproducts at a reduced cost with a proper manufacturing facility attached with uniform clearance between micropunch and microdie. Also, micropunching was demonstrated in the punching of circular and noncircular holes as small as 5 microns in size. Being a mechanical process that does not involve use of chemicals, punching is environment friendly. Therefore, micropunching can be an economic and environment-friendly way of fabricating shaped micro holes in mass production. ${ }^{18-22}$ It is well known that punching is the process of forcing a punch through the material and into a die to create a hole in the work piece. Tool wear is an important issue in micro punching. Even with punches made of hard and tough materials like tungsten-carbide and cobalt (WC/ Co), quality of the punched holes declines rapidly under repeated punching.

Consequently, this research aims at studying the accurate detailed variation of the microholes formed by WC/Co micropunch $(150 \mu \mathrm{m}$ in diameter) in various micro punching periods to explore a more promising method for the microfabrication potential for bioapplications.

\section{Experimental material and procedures}

\section{Experimental material}

Micropunch (Made by Ultrahardness tools company in Japan) with $75 \%$ volume fraction WC particle and $25 \%$ volume fraction Co particle of $50 \mu \mathrm{m}$ mean size, $150 \mu \mathrm{m}$ in diameter, is shown in Figure 1. Pure titanium sheet with $200 \mu \mathrm{m}$ in thickness was used as the substrate. Figure 2 shows the surface microtexture of micropunch and its elements' (Carbon, Tungsten, Cobalt) distribution. Ploughs induced by the ultraprecise machining can be obviously detected, and some debris distribute on the surface of the micropunch. Moreover, the distribution of tungsten element is denser than that of both carbon element and cobalt element, which indicates the hardness of the surface of the micropunch is hard and suitable for the micro punching process.

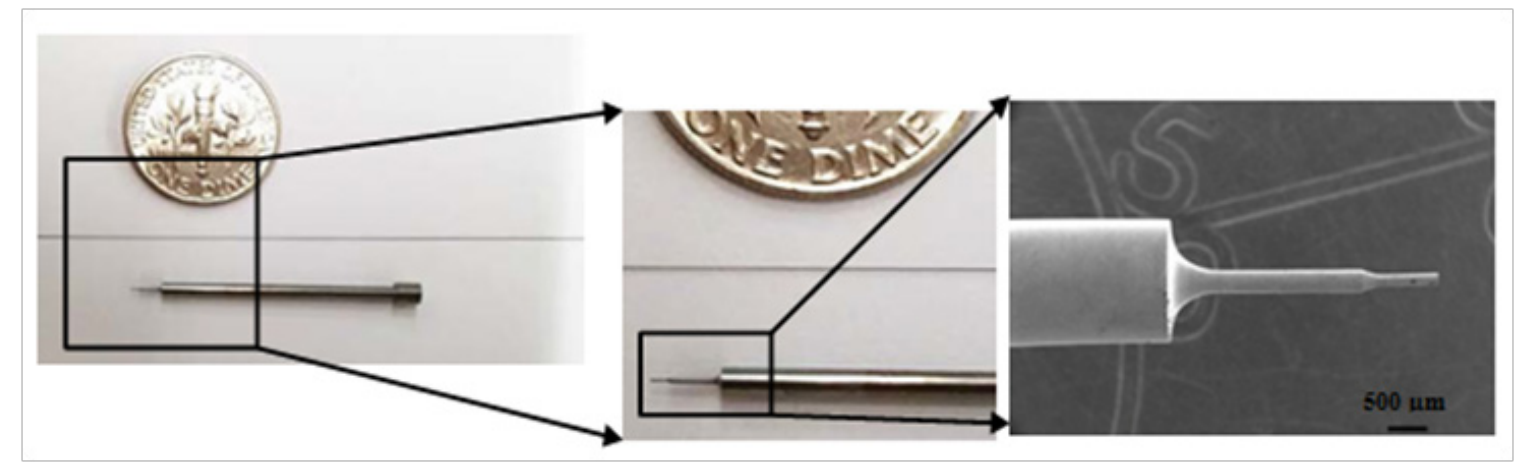

Figure I Profile of $\varnothing 150 \mu \mathrm{m}$ micro punch.
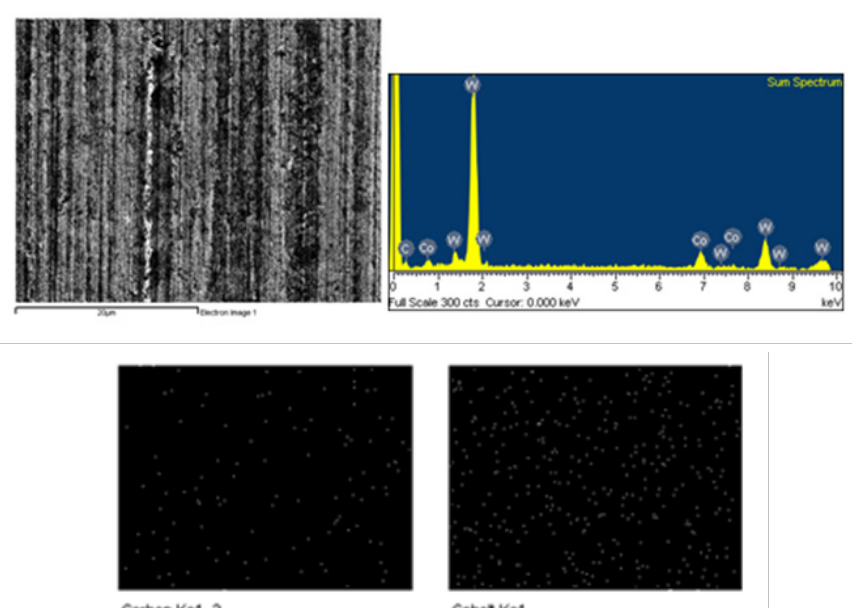

Carbon Ka1_2 Cobot Ka1

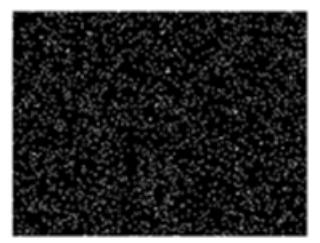

Tungsten Ma1

Figure 2 Surface microtexture of WC+Co micropunch.

\section{Experimental procedures}

The acetone and ethyl alcohol were taken to clean the samples of the titanium sheet carefully to attain the surfaces according to the experimental requirements, and then set the sample into the microdie. Specimens were then punched by the microprocessing machine MP50 (Made in Japan) with 20 pulses per minute with feedrate of $2 \mathrm{~mm}$. The characteristics of microholes punched by $\mathrm{WC}+\mathrm{Co}$ micropunch in different periods were researched by LEXT confocal laser-OLS3000, scanning electron microscopy (SEM), energy dispersive X-ray analysis (EDX), optical surface profiler (OSP)-Veeco/Wyko NT9300, etc.

\section{Results and discussion}

\section{Profile of punched microholes in the initial period}

The morphology of the punched microhole in the initial period (i.e. punching number $<500$ ) is shown in Figure 3. Some debris distribute on both sides of the microhole can be detected obviously, especially for the front side. The relevant EDX results are expressed in Figure 4. It indicates that on the front side, debris include the materials of the micropunch (W, Co, C) and the material of the substrate (Ti). It is worth to note that the elements such as $\mathrm{Na}, \mathrm{Cl}, \mathrm{S}$ and $\mathrm{O}$ are also detected due to the operating contamination in the micropunching. Moreover, the debris distributed on the back side is sparser than that of the front side. The microtexture of the surface of the micropunch during this period is shown in Figure 5 correspondingly. Compared Figure 5 with Figure 2, it illustrates that the wear of micropunch in 
the initial is distinct. The ploughs in the surface of the micropunch become flat during the punching and the tracks of the initial ploughs only distribute sporadically on some areas. In addition, WC particles can hardly be detected. It reveals that the dominant factors of the wear loss in the initial period mainly due to Co loss and the debris distributed originally on the surface of the micropunch at the beginning as shown in Figure 2.

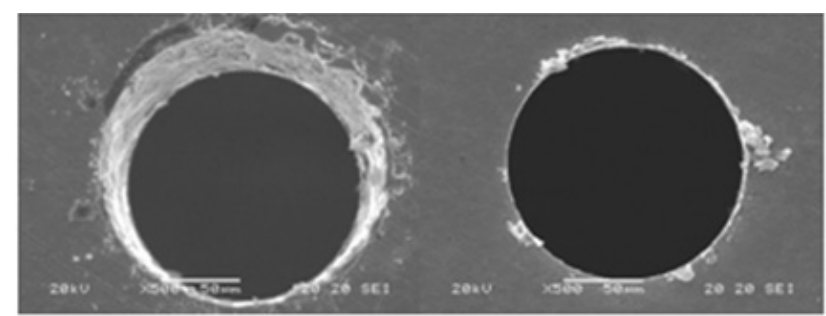

(a) Front side

(b) Back side

Figure 3 Morphology of the punched microhole in the initial period.
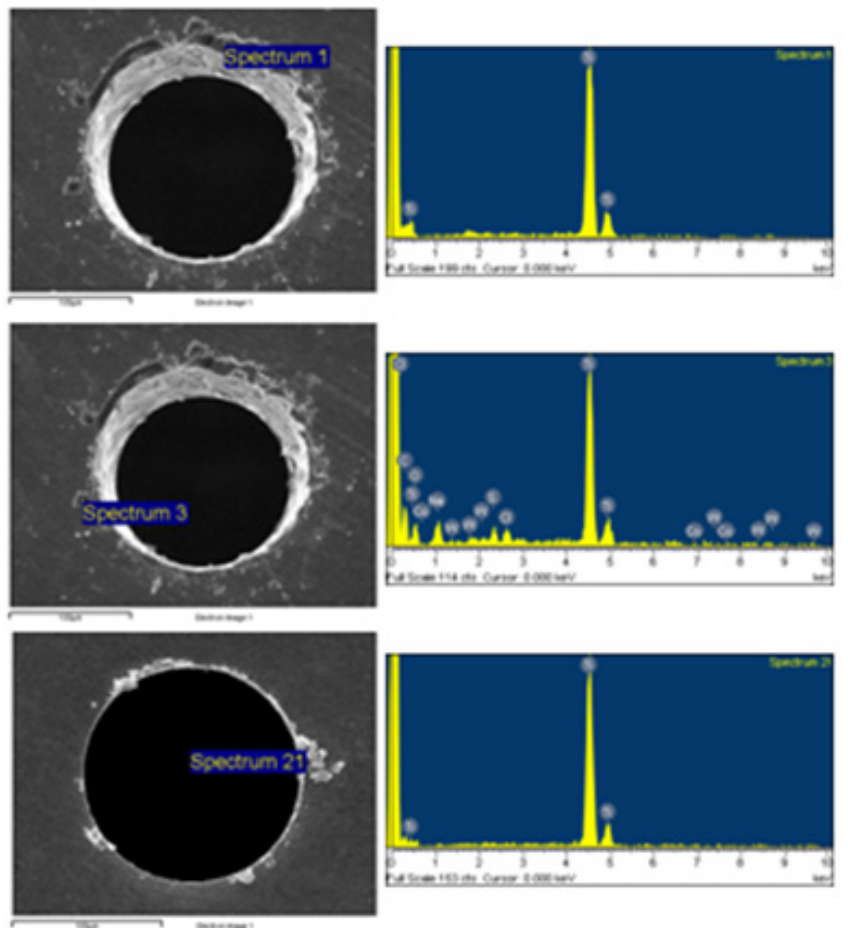

Figure 4 EDX results of debris in the front side and back side.

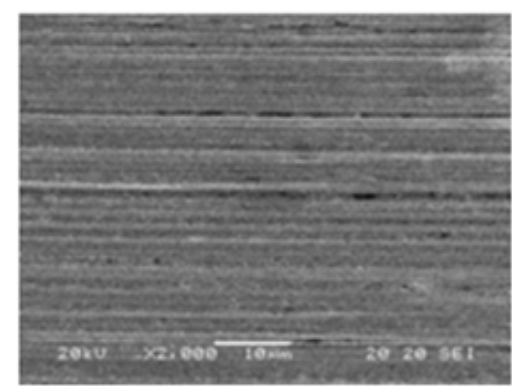

Figure 5 Surface microtexture of the micropunch in the initial period

(Punching number $<500$ ).

\section{Profile of the punched microholes in the quasi-stable period}

The morphology of the punched microhole in the quasi-stable period (the punching number ranges from 500 to 1200) is shown in Figure 6. It shows that the punched microhole is in perfect size with the qualified profile. Although there still sparsely distribute some substrate debris in the backside (Figure 6B), the profile of the punched microhole is definitely superior to that of the initial period (Figure 3) (Figure 6). It elucidates that owing to the effectively combined effect of tungsten carbide and cobalt during the micropunching, the punched microholes have the higher quality along with the little wear loss of micropunch. The microtexture of the micropunch in the quasi-stable period is shown in Figure 7. Pieces of WC particles can be detected clearly on the surface of the micropunch. Moreover, WC particles uniformly distribute on the micropunch surface.

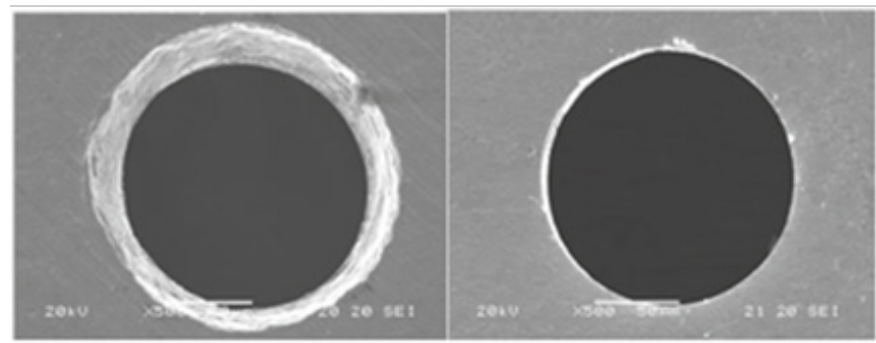

(a) Front side

(b) Back: side

Figure 6 Morphology of the punched microhole in the quasi-stable period.

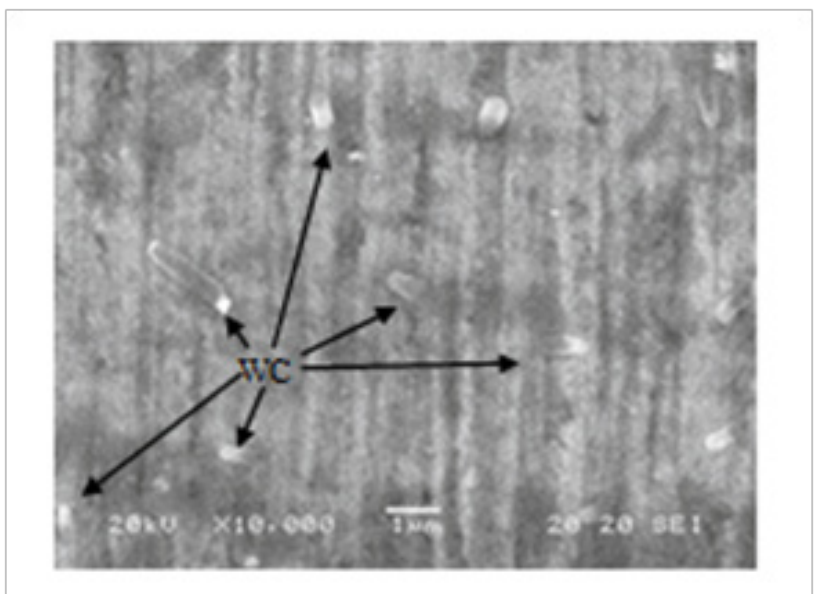

Figure 7 Surface microtexture of WC+Co micropunch in the quasi-stable period.

\section{Profile of the punched microhole in the severe period}

The morphology of the punched microhole (Punching number $>1200$ ) is shown in Figure 8. It shows that the substrate debris attach on both sides, especially in the inner of the microhole as shown in Figure 8A, which actually prevent the practical application of microhole afterwards. Moreover, with the punching process continuing, the micropunch seriously wears. Consequently, the substrate Ti cannot be successfully punched and sticks to the edge of the microhole. In the meantime, with the effect of punching number increment, the unsuccessful removed substrate (i.e. stuck to the edge of the microhole) is sheared and formed the larger debris as shown in 
Figure 8B. In addition, a large amount of micropunch materials are peeled off and adhered to Ti substrate in this intensively severe period as shown in Figure 9. Figure 10 shows the relevant microtexture of the micropunch in the severe period. It shows that a lot of WC particles distribute on the one side of the micropunch surface and the dominant factor of the wear loss in the severe period mainly relies on WC.

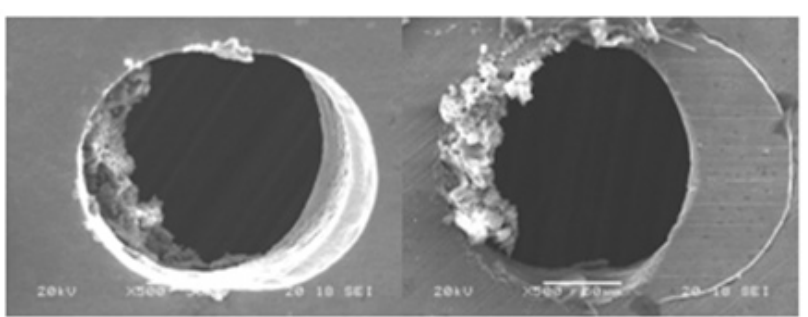

(a) Front side

(b) Back side

Figure 8 Morphology of the punched microhole in the severe period.

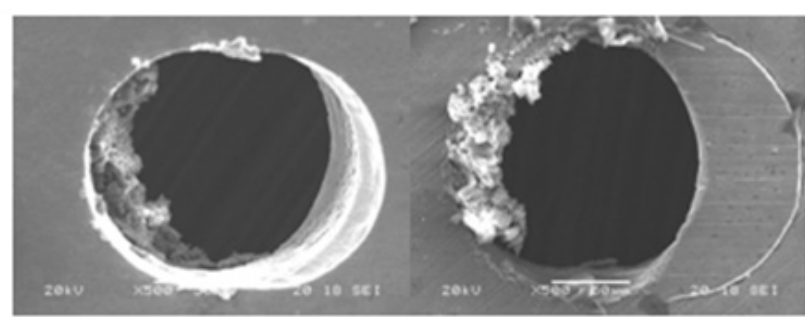

(a) Front side

(b) Back side

Figure 9 Morphology of the punched microhole in the intensively severe period.

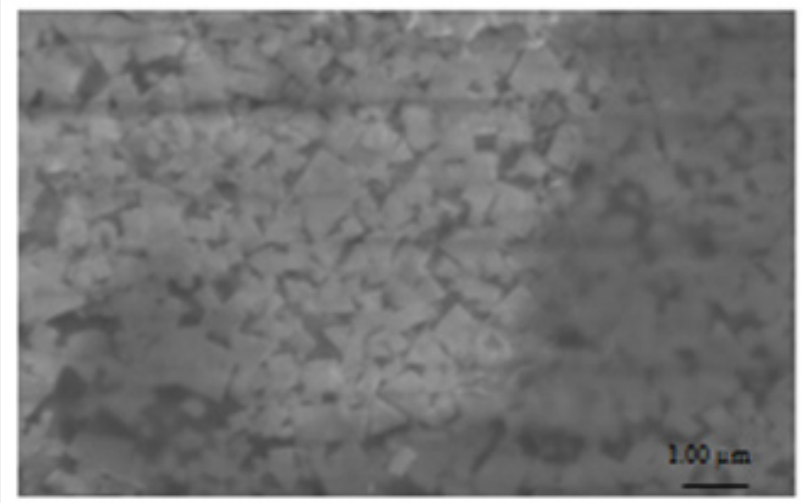

Figure 10 Surface microtexture of micropunch in the severe period.

\section{Diameter variation of punched microholes}

The LEXT confocal laser-OLS3000 was taken for measuring the morphology of the micropunched holes as shown in Figure 11. Figure 12 shows the relevant results (each for 5times) of the diameters of the punched microholes in the micropunching of both front side and back side. The wear loss of the punched microhole at various punching period is shown in Figure 13. It shows that the wear loss of the micropunch in the various periods is distinctive and the diameter of the punched microholes varies correspondingly. Also, the wear loss of the micropunches is consistent with the diameter variation of the microholes. Obvious decrease of the wear loss of the micropunch in the initial period is definitely detected with the apparent change of the diameter of the microhole. Interestingly, the attractive results of the variation of the diameter of the microhole are detected when the punching number ranges from 500 to 1200 . In this period, the diameter of microhole is relatively kept stable due to the un-variation of the micropunch which indicates by the near zero weight loss of the micropunch in the quasistable period. While the micropunching increases further (i.e.>1525) as shown in Figure 12, the diameter of the microhole changes obviously. Meanwhile, the wear loss of the micropunches increases remarkably as a result of the serious loss of cobalt. Due to the lack of cobalt (which is taken as the bonding material with tungsten carbides), the tungsten carbides are easily peeled off. As a result, the diameter of the microholes and the wear loss of the micropunches vary seriously in the severe period of micropunching. Furthermore, with the micropunching process going further, due to the friction between the sample and the micropunch, the temperature of the micropunch will increase. Consequently, the particles of tungsten carbides are more easily peeled off due to the different thermal expansion coefficients of WC and Co. As a result, the wear loss of the micropunch is more intensive in the severe period. Moreover, if the feedrate of the micropunching increases, the more drastic wear loss of the micropunch will appear.

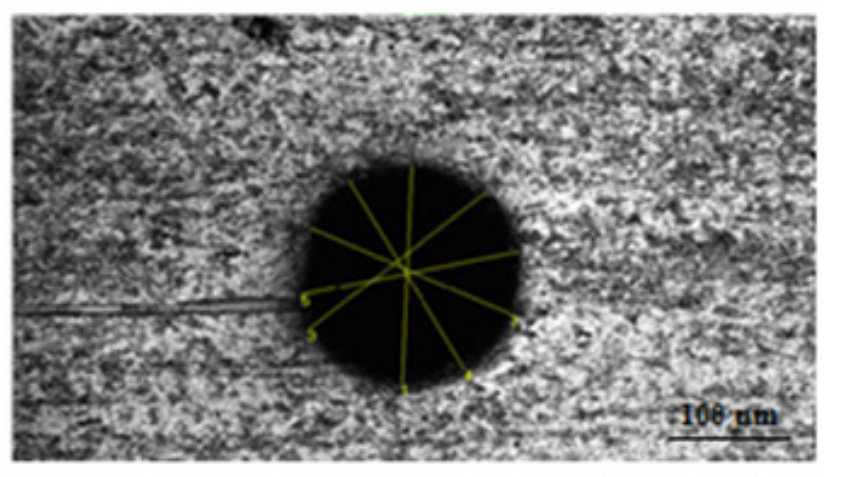

Figure II Profile of microhole punched by WC+Co micropunch measured by OLS3000.

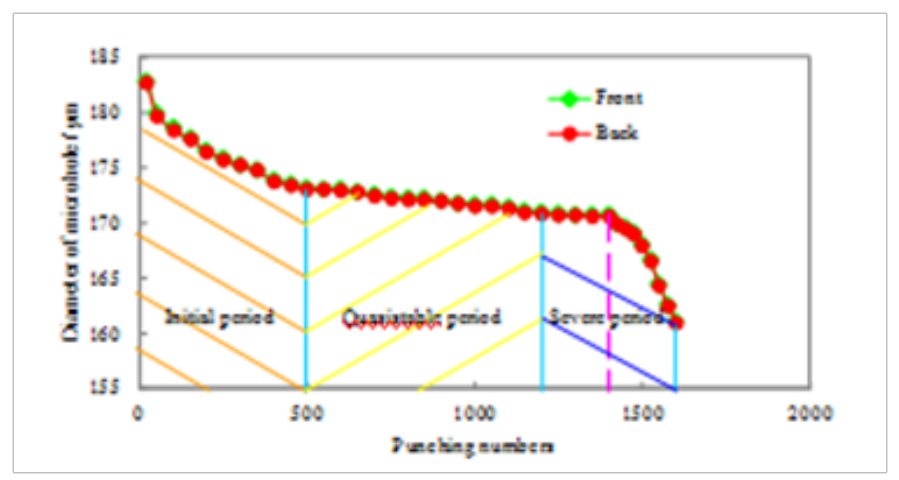

Figure 12 Relationship between diameter of microhole and punching number. 
It should be noted that although the micropunch is in the so-called severe period, the diameter of the punched microhole is still stable to some degree, especially for the punching number between 1200 and 1400, as shown in Figure 12 highlighted with purple dash line. However, the wear of the micropunch in this period starts to increase obviously with the tiny weight loss as shown in Figure 13 highlighted with yellow dash line. The morphology of the relevant punched microhole during this period is shown in Figure 14. It shows that even though the back side of the microhole is comparatively clean, the quality of the punched microhole has already deteriorated with the debris distributed in both outer and inner microhole, especially for the front side as shown in Figure 14A. Moreover, the diameter of the front side of the punched microhole is almost same as that of the back side even in the severe period as shown in Figure 12. It indicates the punched microhole can be used directly without any post treatments. This captivating result definitely pinpoints the outstanding contribution of the micropunch on the fabrication of the near-net shape microholes to meet the challenges in micro manufacturing field, especially for the bioapplications.

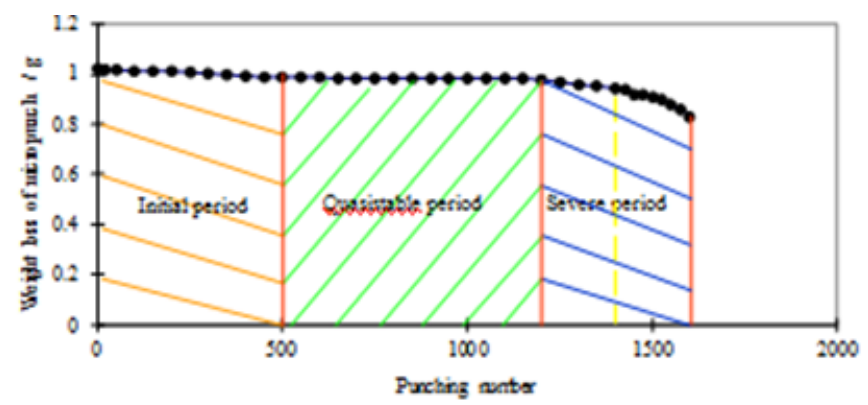

Figure I3 Relationship between wear loss of micropunch and punching numbers.

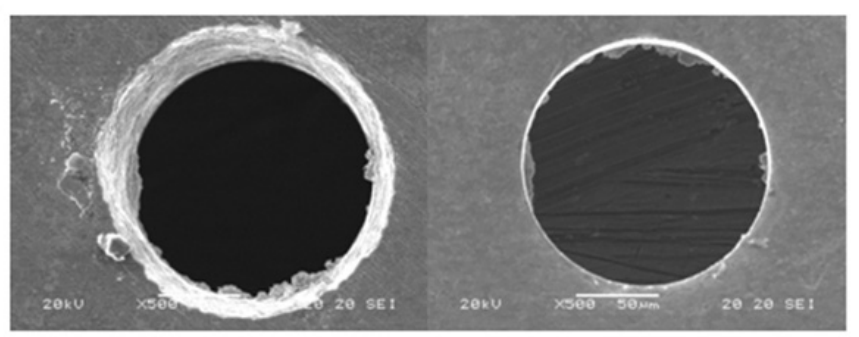

(a) Front side

(b) Back side

Figure I 4 Morphology of the punched microhole in the initial severe period (Punching numbers: 1200 1400).

\section{Conclusion}

The microholes punched successfully by $\mathrm{WC}+\mathrm{Co}$ micropunch ( $150 \mu \mathrm{m}$ in diameter). In the initial micropunching process (punching number $<500$ ), the size of micropunch cannot stabilize because of easily peeled off Co resulted in the significant wear loss of micropunch. When the punching process is in the quasi-stable period (Punching number ranges from 500 to 1200), the punched microholes are of higher quality with the stable size due to the appealing jointcontribution of $\mathrm{WC}+\mathrm{Co}$ of the micropunch along with a little wear loss. When the punching process in the severe period (Punching number exceeds 1525), the size of micropunch are unstable due to the distinct wear loss both of Co and $\mathrm{WC}$ of micropunch resulted in the punched microholes with the lower quality. The interesting unique characteristics of the micropunching is the diameter of the front side of the punched microhole is almost same as that of the back side even in the severe period, which implies the punched microhole can be used directly without any post treatments appealing to meet the challenges in micro manufacturing field related to the bioapplications.

\section{Acknowledgments}

None.

\section{Conflict of interest}

Author declares that there is no conflict of interest.

\section{References}

1. Dornfeld D, Min S, Takeuchi Y. Recent advances in mechanical micromachining. CIRP Annals. 2006;55(2):745-768.

2. Mark JJ. Microfabrication and nanomanufacturing. Boca Raton: FL CRC/ Taylor \& Francis; 2006.

3. Bhattacharyya B. Chapter 12-Recent Advancements in EMM for Micro and Nanofabrication. Electrochemical Micromachining for Nanofabrication. MEMS and Nanotechnology. 2015;219-240.

4. Luttge R. Chapter 2-Basic technologies for microsystems. Nano- and Microfabrication for Industrial and Biomedical Applications. 2016. p. 1154.

5. Knobloch H, Kaminorz Y. MicroNano Integration. Springer-Verlag Berlin: Heidlberg; 2004.

6. Mohamed GH. The MEMS handbook. Boca Raton: FL CRC/Taylor \& Francis; 2006.

7. Edwards SA. The nanotech pioneers. $J$ Angewandte Chemie. 2006;45(43):7116-7117.

8. Oliver G, Henning K, Pieter T. Microsystem engineering of lab-on-a-chip devices. J Angewandte Chemie. 2004;43(34):4382-4390.

9. Johnstone RW, Parameswaran M. An introduction to surfacemicromachining. Netrherlands: Kluwer Academic Publishers; 2004.

10. Mamalis AG. Advanced manufacturing engineering. Journal of Materials Processing Technology. 2005;161:1-9.

11. Janssen PJM, Hoefnagels JPM, de Keijser ThH, et al. Processing induced size effects in plastic yielding upon miniaturization. Journal of the Mechanics and Physics of Solids. 2008;56(8):2687-2706.

12. Uhlmann E, Mullany B, Biermann D, et al. Process chains for highprecision components with micro-scale features. CIRP Annals. 2016;65:549-572.

13. Korkmaz E, Gozen BA, Bediz B, et al. Accurate measurement of micromachining forces through dynamic compensation of dynamometers. Precision Engineering. 2017;49:365-376.

14. Cole KM, Kirk DW, Singh CV, et al. Optimizing electrochemical micromachining parameters for Zr-based bulk metallic glass. Journal of Manufacturing Processes. 2017;25:227-234.

15. Biasetti DA, Di Liscia EJ, Torchia GA. Optical waveguides fabricated in Cr:LiSAF by femtosecond laser micromachining. Optical Materials. 2017;73:25-32.

16. Singh A, Manikandan NA, Sankar MR, et al. Experimental Investigations 
and Surface Morphology of Bio-Micromachining on Copper. Materials Today: Proceedings. 2018;5(2):4225-4234.

17. Saxena KK, Qian J, Reynaerts D. A review on process capabilities of electrochemical micromachining and its hybrid variants. International Journal of Machine Tools and Manufacture. 2018;127:28-56.

18. Lowrie J, Ngaile G. New punch design for the elimination of punch ejection load through manipulation of the elastic strain field in the punch nose. Journal of Manufacturing Processes. 2016;22:49-59.

19. Janča A, Siegl J, Haušild P. Small punch test evaluation methods for material characterization. Journal of Nuclear Materials. 2016; 481:201213.

20. Nguyen TN, Nguyen TT, Pansuk W. Experimental study of the punching shear behavior of high performance steel fiber reinforced concrete slabs considering casting directions. Engineering Structures. 2017;131:564 573

21. Miguel Tortola L, Pallarés L, Miguel PF. Punching shear failure in three-pile caps: Influence of the shear span-depth ratio and secondary reinforcement. Engineering Structures. 2018;155:127-143.

22. Ngaile G, Lowrie J. Punch design for floating based micro-tube hydroforming die assembly. Journal of Materials Processing Technology. 2018;253:168-177. 